\title{
The Kids Are Alright-Right? Physical Activity and Mental Health in College Students
}

\author{
Steven J. Petruzzello and Allyson G. Box
}

\begin{abstract}
The status of physical activity in higher education has changed dramatically over the past 100 years. In this paper, we aim to (a) provide a brief history of physical activity on campus; (b) describe how that activity has changed from a requirement to an elective; (c) illustrate how mental health (particularly stress, anxiety, and depression) has changed in college students over the past few decades; and (d) describe the relationships between physical activity and mental health, particularly in college students. The paper culminates with recommendations for how colleges and universities might facilitate better student mental health through physical activity. There is room to improve the physical activity and mental health of college students, realigning higher education with the promotion of mens sana in corpore sano.
\end{abstract}

Keywords: anxiety, depression, exercise, inactivity, physical education, stress

"Mens sana in corpore sano"- - a healthy mind in a healthy body - is a Latin phrase often attributed either to the Roman poet Juvenal or to the Greek philosopher Thales of Miletus. It has been invoked numerous times in the exercise psychology literature as ancient wisdom that mental health is intimately linked with physical health. Where might such a philosophy resonate more strongly than on a college campus? If the development of young minds is an important mission of the university, then shouldn't it also involve the development of the physical health of these young adults?

\section{A Brief History of Physical Activity on Campus}

Cardinal, Sorensen, and Cardinal (2012) noted that the earliest university physical education program directed by Hitchcock at Amherst College (MA) was "to provide activities that would help Amherst students maintain their health and relieve the strain associated with their 'academic courses"” (p. 503). In perhaps a nod to the ancients, Cardinal et al. quoted Amherst president William Augustus Stearns who stated "Of one thing I am certain, the highest intellectual efficiency can never be reached, the noblest characters will never be formed, till a greater soundness of physical constitution is attained" (p. 503). Not surprisingly, data presented by Cardinal et al. showed that from the early 1920s until 1968, nearly $90 \%$ of 4-year colleges and universities in the United States had some sort of physical activity requirement for graduation. That percentage had slipped to approximately $40 \%$ by $2009-2010$ in the most recent data available (Cardinal et al., 2012). ${ }^{1}$

Consider that Harvard University had a physical training requirement that dated to 1914 (60 hr of physical training required during the freshman year), with the purpose of making freshmen "more conscious of their general health" (Beninger, 1967). During the early 1970s, Harvard had removed the requirement. It is worth noting that Daniel Lieberman, a professor at Harvard, has proposed

The authors are with the Department of Kinesiology and Community Health, University of Illinois Urbana-Champaign, Urbana, IL, USA. Petruzzello (petruzze@illinois.edu) is corresponding author. that Harvard bring back required physical education. He has been quoted as stating:

There's a false division between the mind and the body . . . . The two are intrinsically related and we shouldn't pretend otherwise .... We have all kinds of requirements in language, writing, math, and various mandatory courses within departments for our students. Given the correlation between the mind and the body, how is a physical education requirement any different? (Goldberg, 2016)

Along the same lines, Cardinal has stated "There is a remarkable disconnect in that we fund research as a nation showing that physical activity is absolutely critical to academic and life success, but we aren't applying that knowledge to our own students" (HuffPost, 2013).

\section{Physical Activity Changed From a Requirement to an Elective}

Sparling (2003) noted the prestige of successfully garnering external research funds created a negative cycle: pressure to secure funding led to lack of attention to physical activity programs, and the lack of attention made such programs targets for contraction when university budgets got tight (Sparling, 2003). This situation certainly has not improved over the past 15-20 years and has perhaps been exacerbated by ever-greater pressure on faculty to secure extramural funding. It could also be argued that the increased pressure to become more "academic" shifted focus in departments of physical education (now primarily kinesiology) toward the science of human movement and less on the application of such science. As Park (2017) noted, "The unwarranted decline of university and college physical education departments that were structured to foster both quality research and its proper applications has had many negative effects." (p. 190). She further noted that "Not only are there fewer departments than once existed, but many of these currently give too little (if any) attention to the kinds of courses that are needed to teach people how to put the results of quality research into practice" (p. 187, italics ours). Certainly, 
physical activity options remain available on college campuses, albeit as electives if and when students can fit them into their very tight programs of study. For those few students who choose to take such physical activity courses, the hope is that there is at least some useful transfer into practice of the knowledge being gained in the laboratories.

Perhaps one-way universities have circumvented a need for physical activity requirements, as well as the reduced number of physical activity courses offered by departments, is through the building of relatively lavish recreation centers for students, with the hope that students will use them for their physical activity needs. Data compiled from American College Health Association from Fall 2008 to Spring 2019, using the National College Health Assessment (NCHA), examined the percentage of students who self-reported engaging in sufficient physical activity to meet the guidelines for adults. ${ }^{2}$ During academic year 2008-2009, 46.45\% of students (males $=51.95 \%$; females $=43.80 \%$ ) reported meeting the guidelines. In 2018-2019, that percentage was $44.75 \%$ ( males $=50.15 \%$; females $=42.45 \%$ ). Thus, roughly half of the student population engages in sufficient physical activity, and that doesn't provide information on how many are using the campus fitness facilities. Even if all of these students were utilizing campusbased facilities, more than half of college students are not getting sufficient physical activity (keeping in mind that this is likely an underestimate since it is based on self-report, that is, it is quite likely that much more than half of students are not getting enough physical activity). A study by Bray and Born (2004) examined physical activity patterns during the transition from high school to college. Their findings indicated that $66 \%$ of first-year college students reported engaging in adequate amounts of physical activity during their last 2 months in high school, but this dropped to $44 \%$ during the first 2 months of college. On the other side, $34 \%$ of the students reported insufficient activity during high school, but $56 \%$ reported insufficient activity in college. Thus, the NCHA data are likely reflecting a further decline during the college experience.

One reason to be concerned with these figures is the fact that college physical activity patterns, both active and sedentary, have been shown to persist in the years following graduation (Sparling \& Snow, 2002). Specifically, Sparling and Snow found that $85 \%$ of college seniors who were regularly active were at least as active, if not more active, when surveyed 6 years later; similarly, $81 \%$ of college seniors who were nonexercisers reported the same or less activity 6 years later. This is particularly troubling when taking account of the amount of time spent in sedentary activities by undergraduates. In a systematic review of studies using accelerometers and multi-item questionnaire measures of sedentary time, Moulin, Truelove, Burke, and Irwin (2019) showed that college undergraduates spend anywhere from 8 to $14 \mathrm{hr} /$ day being sedentary. This was confirmed by Castro, Bennie, Vergeer, Bosselut, and Biddle (2020) who showed that, when assessed with accelerometers, university students averaged almost $10 \mathrm{hr}$ /day of sedentary time, primarily from computer use. Moulin et al. (2019) point out that sedentary time in college students is comparable to reports of sedentary time in working-age adults, highlighting the findings from Sparling and Snow of continued levels of (in)activity beyond college. Sparling (2003) argued that physical education in universities has significant potential for education of the college student as well as contributing to prevention of chronic disease.

A further cause for concern lies in the motivation of the individual student. Kim and Cardinal (2018) examined motivational differences in students attending universities with required physical activity education policies and those with an elective physical activity policy. From a sample of nearly 1,000 students (579 having required physical activity and 374 having elective physical activity), the results indicated that requiring physical activity engages students with low levels of self-determined motivation, specifically amotivation (i.e., those less likely to choose activity on their own). By contrast, those students taking elective physical activity had higher levels of self-determined motivation. While certainly not definitive, these results suggest that requiring physical activity may be necessary to reach those individuals who need it most (i.e., the less motivated students). Furthermore, as those students are inherently less self-determined to be active, physical activity educational experiences need to be designed to foster motivational change as well as change in physical activity behavior. Finally, it would be necessary to help students recognize the intrinsically motivating aspects of physical activity for them (e.g., enjoyment) to have the greatest likelihood for them to pursue elective/self-regulated physical activity in the future (see also Kim, Cardinal, \& Yun, 2015). This change toward greater intrinsic motivation might lead to greater use of campus recreational facilities, or at the very least, greater levels of physical activity.

\section{How Mental Health (Particularly Stress, Anxiety, and Depression) Has Changed in College Students Over the Past Few Decades}

Mental health has typically been defined as a state of successful performance of mental function. This results in "productive activities, fulfilling relationships with other people, and the ability to adapt to change and to cope with adversity" (U.S. Department of Health and Human Services, 1999, p. 4). Mental illness, on the other hand, encompasses health conditions "characterized by alterations in thinking, mood, or behavior (or some combination thereof) associated with distress and/or impaired functioning" (USDHHS, p. 4). Said another way, mental illness collectively includes all diagnosable mental disorders. Mental health and mental illness are not dichotomous, but rather they exist on a continuum with health on one end and illness on the other. Mental health problems, farther along this continuum toward mental illness, include signs and symptoms of insufficient intensity or duration to meet criteria for mental illness. However, detection of such problems may warrant active efforts in health promotion, prevention, and treatment.

Stress is defined as "a state of disharmony, or threatened homeostasis" (Chrousos \& Gold, 1992, p. 1,245). Successful coping with that disrupted harmony (i.e., return to homeostasis) results in adaptation. An inability to successfully cope with or adapt to that disrupted homeostasis (i.e., an individual's capacity to cope is exceeded) is usually the precursor to mental health problems, or worse, mental illness. College, including the transition from high school to college as well as college life itself, introduces stress that has the potential to help the student grow intellectually and as a person, but some manage the associated stressors better than others. A study by Bland, Melton, Bigham, and Welle (2014) compiled a list of the most frequently reported life events and daily hassles for college students. The top five life events (with \% of students reporting) were beginning college $(74 \%)$; feelings of uncertainty about the future/future career $(70 \%)$; summer job plans $(63 \%)$; transfer to new university/moving $(63 \%)$; and change in living conditions (61\%; Bland et al., 2014). The top five daily hassles 
were tests $(90 \%)$; text messaging $(88 \%)$; procrastination $(83 \%)$; pressure to do well in school $(83 \%)$; and assignments/papers (79\%; with deadlines, worry about grade-point average, lack of sleep, and time management not very far behind; Bland et al., 2014).

An inability to successfully cope with stress can manifest itself in numerous ways. Common symptoms include irritability or anger, feelings of nervousness or anxiety, fatigue, feelings of depression or sadness, lack of interest or energy, headaches, upset stomach, and muscular tension (American Psychological Association, 2012). Considering the life events and daily hassles that most impact college students, it is worth noting that using data derived from the American College Health Association-National College Health Assessment Executive Summaries showed that from academic years 2008-2009 to 2018-2019, the negative impact of stress on academics increased steadily from $27 \%$ to $33 \%$ (American College Health Association, 2009, 2019). Without adequate or effective stress management strategies, such chronic stress may ultimately lead to anxiety and depression. Again using data from the American College Health Association-National College Health Assessment, anxiety increasingly impacted academics (18\% to $27 \%$ ) as did depression (11\% to $18.5 \%$ ) from 2008 to 2019 (American College Health Association, 2009, 2019). Acharya, Jin, and Collins (2019), in a sample of students from a large Midwestern university, showed that $\sim 47 \%$ of the students had symptoms of depression that were mild-to-severe in nature. These symptoms were significantly related to several stressors, including changes in eating habits, sleep habits, and social activities. Depressive symptoms were also greater in females and international students. Finally, Acharya et al. (2019) noted that students are less likely to seek help for mental health issues or they don't receive that assistance in a timely fashion.

Converging evidence is also seen in data from the Healthy Minds Study (2018), an annual web-based survey which provides a detailed picture of mental health and related issues in college student populations. The 2018-2019 report, from a sample of 62,171 U.S. college students, revealed that $36 \%$ of students reported some level of depression, with $18 \%$ reporting moderate and $18 \%$ reporting severe depression (depression was measured using the Patient Health Questionnaire-9 [Spitzer, Kroenke, Williams, \& Patient Health Questionnaire Primary Care Study Group, 1999], based on symptoms provided in the Diagnostic and Statistical Manual for Mental Disorders for a major depressive episode in the past 2 weeks). ${ }^{3}$ For anxiety, $31 \%$ of the students reported some level of anxiety, with $17 \%$ reporting moderate anxiety and $14 \%$ reporting severe anxiety (anxiety was measured using the GAD-7, a 7-item tool for screening and measuring severity of generalized anxiety disorder in the past 2 weeks [Spitzer, Kroenke, Williams, \& Löwe, 2006]). As with the American College Health Association data, $20-33 \%$ of students reported that emotional or mental difficulties negatively impacted their academic performance on at least $1-2(33 \%)$ and as many as 6 or more days (20\%) over the previous 4 weeks.

The impact of stress, in terms of increasing rates of anxiety and depression, has led to increasing use of mental health services by college students. A study by Lipson, Lattie, and Eisenberg (2019) showed that use of mental health services for all students increased from $19 \%$ in 2007 to $34 \%$ by 2017 . In those students diagnosed with depression, mental health service utilization increased from $42 \%$ in 2007 to $53 \%$ in 2017 . All of this highlights the growing level of mental health problems and illness on college campuses and the increasing burden being placed on student health services.
Such increased utilization could be due to greater mental health challenges or to a reduced stigma in seeking mental health services. Relevant to this point, Gaddis, Ramirez, and Hernandez (2018) showed that stigma in a given college or university is negatively associated with health service utilization (e.g., medication, counseling, therapy, informal support). This work supports the idea that campus-level stigma could be shaped on a given campus by changing the climate around stigma associated with mental health (e.g., mental health education).

\section{Relationships Between Physical Activity and Mental Health}

As already noted, college students report life events and daily hassles that lead to increasing stress (Bland et al., 2014). While not on the list, trying to find time in already busy schedules to fit physical activity in could also be a stressor. Bland et al. (2014) also listed the top coping mechanisms that students reported using to deal with stress. This list includes listening to music, sleeping, relaxing, social support from family and friends, Internet use, social interaction, eating, and social media use, among others (all of these were reported at frequencies of greater than $75 \%$ ). Pertinent to the present paper is the fact that exercise did not appear in the top 10 coping mechanisms. As already noted, less than $50 \%$ of students from the Healthy Minds Study data reported engaging in more than $2 \mathrm{hr} /$ week of moderate- or high-intensity exercise (Healthy Minds Study, 2018).

Recall the earlier discussion of the amount of sedentary time engaged in by college students (Castro et al., 2020; Moulin et al., 2019). Not only does time spent being sedentary have physical health consequences, there are mental health consequences as well. DeMello et al. (2018) showed that amount of sedentary time was related to mood disturbance over the course of 1 year. Specifically, time spent being sedentary was associated with subsequent increased mood disturbance. However, they also showed that mood disturbance was associated with increased sedentary time. By experimentally increasing sedentary time by approximately $30 \mathrm{~min} /$ day, Endrighi, Steptoe, and Hamer (2016) observed an increase in mood disturbance. This increased mood disturbance, in turn, was associated with a larger stress-induced inflammatory response. These findings highlight the notion that too much time being sedentary, a common occurrence in college students, can potentially lead to negative mental health consequences. On the other hand, the work by DeMello et al. (2018) also suggests that negative mental health can be lessened or even improved with less time being sedentary.

What do we know about the impact of physical activity on aspects of mental health in college students? The relationship between physical activity and mental health has been studied for decades, albeit increasingly over the past decade or so. This link is strong enough that physical activity is now promoted as a strategy for maintaining or improving mental health (Rebar \& Taylor, 2017). A study of 1.2 million U.S. adults from 2011 to 2015 that examined the association between exercise and mental health burden showed that all types of exercise (e.g., cycling, aerobics, running, walking) were associated with a reduction in mental health burden (Chekroud et al., 2018). This reduction equated to approximately $12-22 \%$ fewer days of poor mental health when compared with no exercise at all. Chekroud et al. (2018) further showed that any duration of activity was associated with reduced mental health burden, indicating the exercise itself need not be time 
consuming. Similar findings were shown for frequency, with the greatest reduction in burden occurring when exercise was done three to five times per week. In some ways, the findings of Chekroud et al. (2018) echo what has been shown in many studies and summarized in numerous meta-analyses of physical activity and both anxiety (Ensari, Greenlee, Motl, \& Petruzzello, 2015; Petruzzello, Landers, Hatfield, Kubitz, \& Salazar, 1991; Schuch et al., 2019; Stubbs et al., 2017) and depression (Choi et al., 2020; Currier et al., 2020; Schuch et al., 2018), albeit not only in college students. This protective benefit is shown even in those with a genetic risk (Choi et al., 2020). As such, developing physical activity habits during the college years could prevent the development of mental health issues like anxiety and depression into adulthood.

As for how "hard" one should exercise, Gerber et al. (2014) examined the effects of increased intensity of physical activity on stress, pain, depressive symptoms, and sleep in undergraduate students. More specifically, they sought to determine whether vigorous physical activity (VPA) had mental health benefits beyond moderate physical activity (MPA). Gerber et al. (2014) compared students who engaged in vigorous-intensity exercise ( $\geq 20$ min of VPA at least 3 times/week) in addition to the American College of Sports Medicine's MPA recommendations ( $\geq 150$ of MPA/week) with those who only engaged in MPA. Perceived stress, pain, depressive symptoms, and subjective sleep were assessed via questionnaire, and objective sleep was assessed via sleep-electroencephalography assessment, and physical activity was assessed using actigraphy. The results indicated that VPA was associated with less stress, pain, subjective sleep complaints, and depressive symptoms. In addition, VPA was associated with a more favorable objective sleep pattern: increased total sleep time, more Stage 4 and rapid eye movement sleep, more slow wave sleep, and a lower percentage of light sleep. They also examined depressive symptoms when experiencing low and high levels of stress, finding that those engaged in VPA had significantly lower symptoms, particularly when experiencing high stress. This underscores the findings from Currier et al. (2020) wherein increasing the intensity of physical activity (vigorous instead of moderate) from zero to even $1 \mathrm{hr} /$ week significantly reduced, by $32 \%$, the likelihood of depression.

While not all students experience anxiety and depression, stress is certainly a salient aspect of daily college life. Work by von Haaren et al. has examined the extent to which exercise training can potentially attenuate the impacts of such stress. In two reports (von Haaren, Haertel, Stumpp, Hey, \& Ebner-Priemer, $2015,2016), 61$ undergraduate engineering students were randomly assigned to either an exercise intervention (aerobic capacity [reported as $\mathrm{VO}_{2 \max }$ ] increased $\sim 9 \%$ ) or a wait-list control group $\left(\mathrm{VO}_{2} \mathrm{max}\right.$ decreased $\sim 6 \%$ ) for 20 weeks. The students were tested at baseline and during two academic examinations. Although stress reactivity was elevated for both groups during examination periods, emotional reactivity was reduced after the intervention for the Exercise group, as indicated by both less self-reported perceived stress (von Haaren et al., 2015) and greater heart rate variability (von Haaren et al., 2016). These findings were taken as evidence of aerobic exercise as a potentially useful strategy in attenuating the deleterious effects of stress.

Importantly, physical activity does not have to be aerobic to be effective. Kul Karaali, Ilgin, Ozcan, and Kursat (2019) examined the effect of resistive exercise training in undergraduates. Students in both the exercise $(n=20)$ and control $(n=20)$ groups were evaluated (via questionnaire) before and after 8 weeks on their quality of sleep, fatigue, anxiety, and depression. Sleep quality increased, while fatigue and perceived physical limitation decreased for the exercise group (3 days/week, 20-30 min/session); anxiety (slightly) and depression scores also decreased in comparison to the students in the control group.

Beyond anxiety and depression manifestation, stress is expressed psychobiologically (e.g., via cardiovascular [e.g., heart rate, blood pressure] and hormonal [e.g., cortisol] responses). Gerber et al. (2017) examined whether VPA could modify the stress response in undergraduate students. Self-reported stress (rated over the past month) and accelerometry-derived physical activity over 7 days were used to examine responses to an experimental social stress test. Gerber et al. (2017) showed that those students who reported relatively high levels of stress coupled with low VPA had large increases in cortisol in response to the stress test. This subgroup also showed a slower dissipation of cortisol following the stress test, along with more anxiety and negative mood. By contrast, those students reporting high stress coupled with high VPA had a smaller cortisol release to the stress test, and their recovery time was approximately $30 \mathrm{~min}$ shorter over the course of an 80-min time frame following the stress test. The larger reactivity response has implications for the brain as well. Trotman, Gianaros, Veldhuijzen van Zanten, Williams, and Ginty (2019), in a sample of healthy college-aged women, measured cardiovascular reactivity (heart rate, blood pressure, total peripheral resistance) to a psychosocial stress test. The participants were subsequently examined again 1 year later, this time using structural magnetic resonance imaging, to measure the amount of gray matter volume of the amygdala and hippocampus. These two brain regions are thought to influence peripheral stress physiology (e.g., cardiovascular reactivity). The results indicated that those who had greater heart rate and blood pressure reactivity at baseline had smaller volumes of gray matter in the amygdala and hippocampus. Such differences in gray matter volume may increase the likelihood of exaggerated stress responses. Exercise may attenuate this effect. Of note, Puterman et al. (2010) have shown that vigorous exercise can also protect against accelerated cell aging (indexed by shorter telomere length), even when experiencing high perceived stress.

We would be remiss not to mention the well-established relationship between physical activity and brain health. The January 2020 issue of Scientific American highlighted the notion of "active body, active brain" with a feature article titled "Why Your Brain Needs Exercise" (Raichlen \& Alexander, 2020). This is just one example of the ever-increasing attention being given to this relationship (see also Erickson et al., 2019; Hillman, Erickson, \& Kramer, 2008; Stillman et al., 2018 for summaries and research focused on young adult populations). The conundrum we face then is, with all of the available evidence pointing to the benefits of physical activity, particularly for the college-aged individual, why aren't more college students engaging in physical activity? At least part of the answer might lie in whether physical activity is enjoyable. In too many instances, the focus on physical activity, and exercise in particular, is on some specific health outcome (e.g., weight loss). As Pringle put it, "encouraging a love of movement should take precedence over the medicalization and disciplining of the moving body" (2010, p. 124). Such an idea is completely consistent with Hedonic Theory (Young, 1952), the basic premise of which is that we continue to engage in activities that bring pleasure or enjoyment and avoid those that don't. This has been classically shown in the physical activity domain by Williams et al. (2008), where they demonstrated that how people felt during exercise predicted continued involvement 6 and 12 months later 
(for more on the physical activity-affect relationship see also Boyle et al., 2020; Lee, Emerson, \& Williams, 2016; Liao, Chou, Huh, Leventhal, \& Dunton, 2017; Williams, Dunsiger, Jennings, \& Marcus, 2012).

\section{Recommendations for How Colleges and Universities Might Facilitate Better Student Mental Health Through Physical Activity}

In 1960, President-Elect John F. Kennedy wrote:

But the harsh fact of the matter is that there is also an increasingly large number of young Americans who are neglecting their bodies-whose physical fitness is not what it should be-who are getting soft. And such softness on the part of individual citizens can help to strip and destroy the vitality of a nation. For the physical (and mental) vigor of our citizens is one of America's most precious resources. If we waste and neglect this resource, if we allow it to dwindle and grow soft then we will destroy much of our ability to meet the great and vital challenges which confront our people. We will be unable to realize our full potential as a nation. (Kennedy, 1960, p. 16; emphasis added)

This could be written today and be just as true as it was 60 years ago, particularly on our college campuses. Given the myriad health benefits, both physical and mental, of regular physical activity, how do we get our university students to be more regularly active?

One possibility is a return (in most cases) to physical activity as required part of general education in the academy. Over 15 years ago, Sparling (2003) stated: "In recent years, many universities have revitalized an institutional commitment to a broadening of undergraduate curricula to ensure a diversity of coursework. Such a perspective should fundamentally include exposure to quality physical education and physical activity opportunities." (p. 583). A study by Sharp and Barney (2016) examined stress in college students from different universities, one which required (two classes) and one which did not require physical activity classes. They found for "students at both universities, that participation in physical activity classes helped students forget their stressors, increased confidence in handling the stress in their lives, and that they left their activity class not feeling stress." (p. 77). Sharp and Barney concluded that "The results from this study clearly show that physical activity, either required or not required for graduation, is extremely beneficial for college-aged students" (p. 77). But what if, in spite of the calls for re-instituting required physical education as part of the general education (see Cardinal, quoted in HuffPost, 2013; Goldberg, 2016), this is unrealistic or may take some time to re-implement?

The American College of Sports Medicine has had an ongoing Exercise is Medicine ${ }^{\circledR}$ program, which includes an Exercise is Medicine ${ }^{\circledR}$ On Campus (EIM-OC) initiative. As stated in the EIMOC Campus Action Guide (American College of Sports Medicine, 2019), the EIM-OC "calls upon universities and colleges to promote physical activity as a vital sign of health" by encouraging "faculty, staff and students to work together toward improving the health and well-being of the campus community" (p. 3). Steps for implementation include changing campus culture to include movement as an important part of the daily culture and giving students the tools they need to develop healthy and hopefully lifelong physical activity habits. Other steps include the assessment of physical activity whenever students visit their campus health care provider as well as making connections between campus health care providers and health/fitness professionals in order to implement and utilize a referral system for exercise prescription. These latter two points, while they make sense when a student might present with mental health problems, perhaps put too much emphasis on what Pringle (2010) referred to as physical activity being used as "medicalization" of the body. There is certainly a space for using physical activity as a treatment for health problems (i.e., treatment), but it perhaps makes even more sense to focus on physical activity for its preventive effects instead. In addition to the preventive ill-health effects of physical activity, the EIM-OC initiative could also be a place where the meaningful pleasurable and enjoyable aspects of physical activity could be highlighted. Of course, these may be different for individual students, but if the student focus can be directed toward such aspects of physical activity, they would be more likely to develop greater levels of intrinsic motivation to engage in regular physical activity (see also Kim et al., 2015). This could thus lead to a greater likelihood of lifetime physical activity (refer back to Sparling \& Snow, 2002).

To that end, how can physical activity and movement become part of the campus culture? The three most obvious ways include the built environment, active transportation, and outdoor activity. Returning again to Sparling (2003), he stated that the university campus:

provides a "built environment" that is favorable to establishing regular patterns of physical activity and exercise (i.e., extensive facilities, intramurals, sports clubs, credit and non-credit exercise classes, pedestrian campuses). Most campuses provide the key physical environmental factors known to be positively associated with participation in physical activityaccessibility to facilities, opportunities for activity, safety, and aesthetic attributes. (p. 584)

Such a built environment can facilitate active transportation by enhancing walking and cycling paths, closing campuses to vehicle traffic, and perhaps creatively providing natural environments within the campus. While certainly not a guarantee, this facilitation of active transportation might carryover when the student graduates and moves on to their post-graduation life. Meredith et al. (2020), based on a scoping review, concluded that as little as 10 min of walking in natural (outdoor) environments had positive impacts on mental health in college students. They further suggested that universities "... should strongly consider providing access to nature on their campuses" (p. 13). This is consistent with a review of "green" exercise (i.e., exercise outdoors or in nature), which indicated that, compared with indoor exercise, outdoor exercise may result in more pleasant affect and be more enjoyable (Lahart, Darcy, Gidlow, \& Calogiuri, 2019). Much more work needs to be done to explore these effects, but the potentially positive impact is promising.

Practically then, universities need to provide opportunities for students to incorporate physical activity into their daily routines. However, as Hook and Markus (2020) point out "Rather than simply encouraging people to make better choices in the face of considerable social, practical, and material barriers, it is often more effective to address upstream factors - to change the environment in ways that make healthy behaviors easier and unhealthy behaviors harder to do" (p. 644). With this in mind, while physical and mental health is the student's responsibility, institutions of higher education need to help create the "culture cycle" (Hook \& Markus, 2020) to make health and wellness realistic. Creating a wellness culture on campuses (e.g., EIM-OC) could include physical 
changes (i.e., the built environment) to increase the likelihood of physical activity, but changing the physical environment can be time-consuming, costly, and difficult (e.g., many campus buildings are older and would be difficult to modify). Instituting, or reinstituting, physical activity as part of general education requirements can be a reflection, and reinforcement, of this health and wellness culture. However, these courses should be educational, providing students not only with the opportunity for physical activity but also with the tools necessary to strengthen healthy physical activity habits that can last a lifetime. Such physical activity courses should help students learn about and develop healthy physical activity habits, in part through helping them discover personally enjoyable physical activity pursuits. A healthier student body would also put less strain on student health services. This culture shift might help us get closer to the ideal of mens sana in corpore sano.

\section{Conclusion}

When students graduate from colleges and universities, we assume they are prepared to take on their roles as contributing members of society in whatever professions they have chosen. We should also have prepared them for the transition into often less physical activity friendly environments, both physically and socially. If we have done our job effectively, they might be better prepared to continue their physical activity habits. Even better, they might be prepared to be agents of change in their own right, either directly or indirectly, by helping to change cultural norms and attitudes toward physical activity. So, are the kids alright? For the most part they may be, but we can certainly do better to reduce the number of those who aren't and increase the number who are.

\section{Endnotes}

1. This has likely slipped even further since 2010 (B. J. Cardinal, personal communication, January 24, 2020).

2. Moderate-intensity cardio or aerobic exercise for at least $30 \mathrm{~min}$ on 5 or more days/week or vigorous-intensity cardio or aerobic exercise for at least $20 \mathrm{~min}$ on 3 or more days/week (Haskell et al., 2007).

3. The ACHA figures for depression are consistent with a systematic review of prevalence in university students globally (weighted mean prevalence $=30.6 \%$; Ibrahim, Kelly, Adams, \& Glazebrook, 2013).

\section{Acknowledgments}

We would like to acknowledge the undergraduate students who worked in the Exercise Psychophysiology Laboratory for their help in organizing the search for relevant literature. Rowan Olson deserves special mention in this regard.

\section{References}

Acharya, L., Jin, L., \& Collins, W. (2019). College life is stressful today: Emerging stressors and depressive symptoms in college students. Journal of American College Health, 66(7), 655-664. doi:10.1080/ 07448481.2018.1451869

American College Health Association. (2009). American College Health Association-National College Health Assessment II: Reference group executive summary Fall 2008. Baltimore, MD: American College Health Association.
American College Health Association. (2019). American College Health Association-National College Health Assessment II: Reference group executive summary Spring 2019. Silver Spring, MD: American College Health Association.

American College of Sports Medicine. (2019). Exercise is Medicine On Campus action guide. Retrieved from https://www.exerciseis medicine.org/assets/page_documents/EIM\%20on\%20Campus $\% 20$ action\%20guide.pdf

American Psychological Association. (2012). Stress in America ${ }^{\mathrm{TM}}$ : Our health at risk. Retrieved from https://www.apa.org/news/press/ releases/stress/2011/final-2011.pdf

Beninger, J.R. (1967, February 10). Freshman PT requirement-Why bother? The Crimson. Retrieved from https://www.thecrimson.com/ article/1967/2/10/freshman-pt-requirement-why-bother/

Bland, H.W., Melton, B.F., Bigham, L.E., \& Welle, P.D. (2014). Quantifying the impact of physical activity on stress tolerance in college students. College Student Journal, 48(4), 559-568.

Boyle, H.K., Dunsiger, S.I., Bohlen, L.C., Emerson, J.A., Lee, H.H., Stevens, C.J., \& Williams, D.M. (2020). Affective response as a mediator of the association between the physical and social environment and activity behavior. Journal of Behavioral Medicine, 43, 773-782. doi:10.1007/s10865-019-00118-0

Bray, S.R., \& Born, H.A. (2004). Transition to university and vigorous physical activity: Implications for health and psychological wellbeing. Journal of American College Health, 52(4), 181-188. PubMed ID: 15018429 doi:10.3200/JACH.52.4.181-188

Cardinal, B.J., Sorensen, S.D., \& Cardinal, M.K. (2012). Historical perspective and current status of the physical education graduation requirement at American 4-year colleges and universities. Research Quarterly for Exercise \& Sport, 83(4), 503-512. PubMed ID: 23367812 doi:10.1080/02701367.2012.10599139

Castro, O., Bennie, J., Vergeer, I., Bosselut, G., \& Biddle, S.J.H. (2020). How sedentary are university students? A systematic review and meta-analysis. Prevention Science, 21(3), 332-343. PubMed ID: 31975312 doi:10.1007/s11121-020-01093-8

Chekroud, S.R., Gueorguieva, R., Zheutlin, A.B., Paulus, M., Krumholz, H.M., Krystal, J.H., \& Chekroud, A.M. (2018). Association between physical exercise and mental health in 1.2 million individuals in the USA between 2011 and 2015: A cross-sectional study. Lancet Psychiatry, 5(9), 739-746. PubMed ID: 30099000 doi:10.1016/ S2215-0366(18)30227-X

Choi, K.W., Zheutlin, A.B., Karlson, R.A., Wang, M., Dunn, E.C., Stein, M.B., .. Smoller, J.W. (2020). Physical activity offsets genetic risk for incident depression assessed via electronic health records in a biobank cohort study. Depression \& Anxiety, 37(2), 106-114. PubMed ID: 31689000 doi:10.1002/da.22967

Chrousos, G.P., \& Gold, P.W. (1992). The concepts of stress and stress system disorders: Overview of physical and behavioral homeostasis. Journal of the American Medical Association, 267(9), 1244-1252. PubMed ID: 1538563 doi:10.1001/jama.1992.03480090092034

Currier, D., Lindner, R., Spittal, M.J., Cvetkovski, S., Pirkis, J., \& English, D.R. (2020). Physical activity and depression in men: Increased activity duration and intensity associated with lower likelihood of current depression. Journal of Affective Disorders, 260, 426-431. PubMed ID: 31539676 doi:10.1016/j.jad.2019.09.061

DeMello, M.M., Pinto, B.M., Dunsiger, S.I., Shool, R.P., Burgess, S., Hand, G.A., \& Blair, S.N. (2018). Reciprocal relationship between sedentary behavior and mood in young adults over one-year duration. Mental Health \& Physical Activity, 14, 157-162. doi:10.1016/j.mhpa. 2017.12.001

Endrighi, R., Steptoe, A., \& Hamer, M. (2016). The effect of experimentally induced sedentariness on mood and psychobiological responses 
to mental stress. British Journal of Psychiatry, 208(3), 245-251. PubMed ID: 26294364 doi:10.1192/bjp.bp.114.150755

Ensari, I., Greenlee, T.A., Motl, R.W., \& Petruzzello, S.J. (2015). Metaanalysis of acute exercise effects on state anxiety: An update of randomized controlled trials over the past 25 years. Depression \& Anxiety, 32(8), 624-634. PubMed ID: 25899389 doi:10.1002/da. 22370

Erickson, K.I., Hillman, C., Stillman, C.M., Ballard, R.M., Bloodgood, B., Conroy, D.E., ... Powell, K.E. (2019). Physical activity, cognition, and brain outcomes: A review of the 2018 Physical Activity Guidelines. Medicine \& Science in Sports \& Exercise, 51(6), 1242-1251. PubMed ID: 31095081 doi:10.1249/MSS. 0000000000001936

Gaddis, S.M., Ramirez, D., \& Hernandez, E.L. (2018). Contextualizing public stigma: Endorsed mental health treatment stigma on college and university campuses. Social Science \& Medicine, 197, 183-191. PubMed ID: 29248824 doi:10.1016/j.socscimed.2017.11.029

Gerber, M., Brand, S., Herrmann, C., Colledge, F., Holsboer-Trachsler, E., \& Pühse, U. (2014). Increased objectively assessed vigorousintensity exercise is associated with reduced stress, increased mental health and good objective and subjective sleep in young adults. Physiology \& Behavior, 135, 17-24. PubMed ID: 24905432 doi: 10.1016/j.physbeh.2014.05.047

Gerber, M., Ludyga, S., Mücke, M., Colledge, F., Brand, S., \& Pühse, U. (2017). Low vigorous physical activity is associated with increased adrenocortical reactivity to psychosocial stress in students with high stress perceptions. Psychoneuroendocrinology, 80, 104-113. PubMed ID: 28324699 doi:10.1016/j.psyneuen.2017.03.004

Goldberg, C. (2016, August 26). Required to run? Professor proposes Harvard bring back required phys ed. CommonHealth. Retrieved from https://www.wbur.org/commonhealth/2016/08/26/harvardprofessor-phys-ed-required

Haskell, W.L., Lee, I.M., Pate, R.R., Powell, K.E., Blair, S.N., Franklin, B.A., ... American College of Sports Medicine; American Heart Association. (2017). Physical activity and public health: Updated recommendation for adults from the American College of Sports Medicine and the American Heart Association. Circulation, 116(9), 1081-1093. doi:10.1161/CIRCULATIONAHA.107.185649

Healthy Minds Study. (2018). The healthy minds study: 2018-2019 data report. Retrieved from https://healthymindsnetwork.org/wp-content/ uploads/2019/09/HMS_national-2018-19.pdf

Hillman, C.H., Erickson, K.I., \& Kramer, A.F. (2008). Be smart, exercise your heart: Exercise effects on brain and cognition. Nature Reviews Neuroscience, 9(1), 58-65. PubMed ID: 18094706 doi:10.1038/ nrn2298

Hook, C.J., \& Markus, H.R. (2020). Health in the United States: Are appeals to choice and personal responsibility making Americans sick? Perspectives on Psychological Science, 15(3), 643-664. PubMed ID: 32097096 doi:10.1177/1745691619896252

HuffPost. (2013, January 7). Mandatory physical education in colleges and universities is at an all-time low, report shows. Huffpost. Retrieved from https://www.huffpost.com/entry/physical-educationcollege-university-mandatory_n_2425627?guccounter=1

Ibrahim, A.K., Kelly, S.J., Adams, C.E., \& Glazebrook, C. (2013). A systematic review of studies of depression prevalence in university students. Journal of Psychiatric Research, 47(3), 391-400. PubMed ID: 23260171 doi:10.1016/j.jpsychires.2012.11.015

Kennedy, J.F. (1960). The soft American. Sports Illustrated, 13(26), 13-17.

Kim, M., Cardinal, B.J., \& Yun, J. (2015). Enhancing student motivation in college and university physical activity courses using instructional alignment practices. Journal of Physical Education,
Recreation \& Dance, 86(9), 33-38. doi:10.1080/07303084.2015. 1085343

Kim, M.S., \& Cardinal, B.J. (2018). Differences in university students' motivation between a required and an elective physical activity education policy. J American College Health, 67(3), 207-214. doi: 10.1080/07448481.2018.1469501

Kul Karaali, H., Ilgin, D., Ozcan, O., \& Kursat, S. (2019). Resistive exercises as a healthy life style behaviour on university students' lifespan. Eurasian Journal of Medical Investigation, 3(4), 285-292. doi:10.14744/ejmi.2019.72458

Lahart, I., Darcy, P., Gidlow, C., \& Calogiuri, G. (2019). The effects of green exercise on physical and mental wellbeing: A systematic review. International Journal of Environmental Research \& Public Health, 16(8), 1352. doi:10.3390/ijerph16081352

Lee, H.H., Emerson, J.A., \& Williams, D.M. (2016). The exercise-affectadherence pathway: An evolutionary perspective. Frontiers in Psychology, 7, 1285. PubMed ID: 27610096 doi:10.3389/fpsyg.2016. 01285

Liao, Y., Chou, C-P., Huh, J., Leventhal, A., \& Dunton, G. (2017). Examining acute bi-directional relationships between affect, physical feeling states, and physical activity in free-living situations using electronic ecological momentary assessment. Journal of Behavioral Medicine, 40(3), 445-457. PubMed ID: 27766481 doi:10.1007/ s10865-016-9808-9

Lipson, S.K., Lattie, E.G., \& Eisenberg, D. (2019). Increased rates of mental health service utilization by U.S. college students: 10-Year population-level trends (2007-2017). Psychiatric Services, 70(1), 60-63. PubMed ID: 30394183 doi:10.1176/appi.ps.201800332

Meredith, G.R., Rakow, D.A., Eldermire, E.R.B., Madsen, C.G., Shelley, S.P., \& Sachs, N.A. (2020). Minimum time dose in nature to positively impact the mental health of college-aged students, and how to measure it: A scoping review. Frontiers in Psychology, 10, 2942. PubMed ID: 31993007 doi:10.3389/fpsyg.2019.02942

Moulin, M.S., Truelove, S., Burke, S.M., \& Irwin, J.D. (2019). Sedentary time among undergraduate students: A systematic review. Journal of American College Health. Advance online publication. doi:10.1080/ 07448481.2019.1661422

Park, R.J. (2017). Is today's physical education the legacy that Franklin Henry had hoped for? Kinesiology Review, 6(2), 187-194. doi:10. 1123/kr.2017-0010

Petruzzello, S.J., Landers, D.M., Hatfield, B.D., Kubitz, K.A., \& Salazar, W. (1991). A meta-analysis on the anxiety-reducing effects of acute and chronic exercise. Sports Medicine, 11(3), 143-182. PubMed ID: 1828608 doi:10.2165/00007256-19911103000002

Pringle, R. (2010). Finding pleasure in physical education: A critical examination of the educative value of positive movement affects. Quest, 62(2), 119-134. doi:10.1080/00336297.2010.10483637

Puterman, E., Lin, J., Blackburn, E., O’Donovan, A., Adler, N., \& Epel, E. (2010). The power of exercise: Buffering the effect of chronic stress on telomere length. PLoS One, 5(5), e10837. PubMed ID: 20520771 doi:10.1371/journal.pone.0010837

Raichlen, D.A., \& Alexander, G.E. (2020). Why your brain needs exercise. Scientific American, 322(1). Retrieved from https://www.scientific american.com/article/why-your-brain-needs-exercise/

Rebar, A.L., \& Taylor, A. (2017). Physical activity and mental health: It is more than just a prescription. Mental Health \& Physical Activity, 13, 77-82. doi:10.1016/j.mhpa.2017.10.004

Schuch, F.B., Stubbs, B., Meyer, J., Heissel, A., Zech, P., Vancampfort, D., ... Hiles, S.A. (2019). Physical activity protects from incident anxiety: A meta-analysis of prospective studies. Depression \& Anxiety, 36, 84-858. doi:10.1002/da.22915 
Schuch, F.B., Vancampfort, D., Firth, J., Rosenbaum, S., Ward, P.B., Silva, E.S., ... Stubbs, B. (2018). Physical activity and incident depression: A meta-analysis of prospective cohort studies. American Journal of Psychiatry, 175(7), 631-648. PubMed ID: 29690792 doi:10.1176/appi.ajp.2018.17111194

Sharp, E., \& Barney, D. (2016). Required and non-required college physical activity classes effect on college students' stress. American Journal of Health Studies, 31(2), 74-81.

Sparling, P.B. (2003). College physical education: An unrecognized agent of change in combating inactivity-related diseases. Perspectives in Biology \& Medicine, 46(4), 579-587. PubMed ID: 14593225 doi: 10.1353/pbm.2003.0091

Sparling, P.B., \& Snow, T.K. (2002). Physical activity patterns in recent college alumni. Research Quarterly for Exercise \& Sport, 73(2), 200-205. PubMed ID: 12092895 doi:10.1080/02701367.2002. 10609009

Spitzer, R.L., Kroenke, K., Williams, J.B., \& Löwe, B. (2006). A brief measure for assessing generalized anxiety disorder: The GAD-7. Archives of Internal Medicine, 166(10), 1092-1097. PubMed ID: 16717171 doi:10.1001/archinte.166.10.1092

Spitzer, R.L., Kroenke, K., Williams, J.B., \& Patient Health Questionnaire Primary Care Study Group. (1999). Validation and utility of a selfreport version of PRIME-MD: The PHQ primary care study. JAMA, 282(18), 1737-1744. doi:10.1001/jama.282.18.1737

Stillman, C.M., Uyar, F., Huang, H., Grove, G.A., Watt, J.C., Wollam, M.E., \& Erickson, K.I. (2018). Cardiorespiratory fitness is associated with enhanced hippocampal functional connectivity in healthy young adults. Hippocampus, 28(3), 239-247. PubMed ID: 29341303 doi: 10.1002/hipo.22827

Stubbs, B., Vancampfort, D., Rosenbaum, S., Firth, J., Cosco, T., Veronese, N., ... Schuch, F.B. (2017). An examination of the anxiolytic effects of exercise for people with anxiety and stress-related disorders: A meta-analysis. Psychiatry Research, 249, 102-108. PubMed ID: 28088704 doi:10.1016/j.psychres.2016.12.020
Trotman, G.P., Gianaros, P.J., Veldhuijzen van Zanten, J.J.C.S., Williams, S.E., \& Ginty, A.T. (2019). Increased stressor-evoked cardiovascular reactivity is associated with reduced amygdala and hippocampus volume. Psychophysiology, 56(1), e13277. PubMed ID: 30132921 doi:10.1111/psyp.13277

U.S. Department of Health and Human Services. (1999). Mental health: A report of the surgeon general. Rockville, MD: National Institute of Mental Health.

von Haaren, B., Haertel, S., Stumpp, J., Hey, S., \& Ebner-Priemer, U. (2015). Reduced emotional stress reactivity to a real-life academic examination stressor in students participating in a 20 -week aerobic exercise training: A randomized controlled trial using ambulatory assessment. Psychology of Sport \& Exercise, 20, 67-75. doi:10.1016/ j.psychsport.2015.04.004

von Haaren, B., Ottenbacher, J., Muenz, J., Neumann, R., Boes, K., \& Ebner-Priemer, U. (2016). Does a 20-week aerobic exercise training programme increase our capabilities to buffer real-life stressors? A randomized, controlled trial using ambulatory assessment. European Journal of Applied Physiology, 116(2), 383-394. doi:10.1007/ s00421-015-3284-8

Williams, D.M., Dunsiger, S., Ciccolo, J.T., Lewis, B.A., Albrecht, A.E., \& Marcus, B.H. (2008). Acute affective response to a moderateintensity exercise stimulus predicts physical activity participation 6 and 12 months later. Psychology of Sport \& Exercise, 9(3), 231-245. PubMed ID: 18496608 doi:10.1016/j.psychsport.2007. 04.002

Williams, D.M., Dunsiger, S., Jennings, E.G., \& Marcus, B.H. (2012). Does affective valence during and immediately following a 10-min walk predict concurrent and future physical activity? Annals of Behavioral Medicine, 44(1), 43-51. PubMed ID: 22532005 doi: 10.1007/s12160-012-9362-9

Young, P.T. (1952). The role of hedonic processes in the organization of behavior. Psychological Review, 59(4), 249-262. PubMed ID: 14949283 doi: $10.1037 / \mathrm{h} 0057176$ 